Wind Energ. Sci. Discuss., doi:10.5194/wes-2016-57, 2017

Manuscript under review for journal Wind Energ. Sci.

Published: 12 January 2017

(c) Author(s) 2017. CC-BY 3.0 License.

(c) (i)

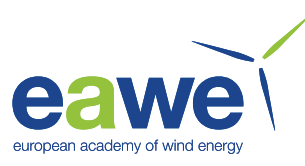

\title{
Flow angle measurement of a yawed turbine and comparison to models
}

\author{
Tyler Gallant ${ }^{1}$ and David A. Johnson ${ }^{1}$ \\ ${ }^{1}$ Wind Energy Group, Mechanical and Mechatronics Engineering, University of Waterloo, 200 University Ave W, Waterloo, \\ Canada N2L 3G1
}

Correspondence to: David A. Johnson (David.Johnson@uwaterloo.ca)

\begin{abstract}
The torque generated by a wind turbine blade is dependent on several parameters, one of which is the angle of attack. Several models for predicting the angle of attack in yawed conditions have been proposed in the literature, but there is a lack of experimental data to use for direct validation.

To address this problem, experiments were conducted under controlled conditions at the University of Waterloo Wind Generation Research Facility using a $3.4 \mathrm{~m}$ diameter test turbine. A five-hole pressure probe was installed in a modular 3D printed blade and was used to measure the angle of attack, $\alpha$, as a function of several parameters. Local flow angle measurements for all azimuthal angles were obtained at radial positions of $r / R=0.55$ and 0.72 at tip speed ratios $(\lambda)$ of 5.0, 3.6, and 3.1. The yaw offset of the turbine was varied from $-15^{\circ}$ to $+15^{\circ}$. Span-wise flow angle measurements are presented for the $r / R=0.55$ cases, and show the variation in radial flow direction throughout yawed rotation.

Experimental results were compared directly to angle of attack values calculated using a model proposed by Morote in 2015. Modeled values were found to be in close agreement with the experimental results. The angle of attack was shown to vary cyclically in the yawed case while remaining mostly constant when aligned with the flow, as expected.

These five-hole probe measurements were also used to characterize the upstream flow profile. Wind speeds determined using the five-hole probe measurements are presented and are in agreement with measurements obtained in the wind facility during testing. The quality of results indicates the potential of the developed instrument for wind turbine measurements.
\end{abstract}

\section{Introduction}

As developments in wind turbine design continue, so too does the need for accurate experimentation and testing of new wind turbine blade designs. One variable that has a critical impact on the performance of a wind turbine blade is the angle of attack, which is directly related to the forces generated on the blade. Conventionally during wind turbine testing, the upstream wind speed is measured via a separate meteorological tower upstream of the turbine, and this wind speed is used in combination with the wind turbine geometry and operational characteristics to model the angle of attack. However, upstream wind speed measurements do not accurately represent the wind speed at the turbine blades for many reasons including the axial induction of the rotor. The angle of attack is therefore calculated using models (e.g. the blade-element momentum method) using 
Wind Energ. Sci. Discuss., doi:10.5194/wes-2016-57, 2017

Manuscript under review for journal Wind Energ. Sci.

Published: 12 January 2017

(c) Author(s) 2017. CC-BY 3.0 License.

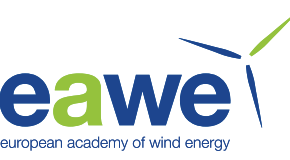

measurements several steps removed from the leading edge of the blade. The result is a lack of accurate experimental data for validating theoretical models.

To address this problem, a five-hole pressure probe has been mounted to the leading edge of a rotating wind turbine blade to accurately measure the local flow angle (LFA) to determine the angle of attack, $\alpha$, in the rotational plane. Experiments were conducted to measure the variation in $\alpha$ as a function of the azimuthal angle of the blade, $\phi$, the tip speed ratio $\lambda$, and the yaw angular position, $\gamma$. Experimental results were then compared to theoretical results calculated using a model proposed by Morote (2015). Span-wise flow angle measurements and the upstream wind profile were also measured.

\section{Background}

The use of five-hole pressure probes to measure the wind turbine blade angle of attack and span-wise flow angle is not a new concept, though the method is relatively uncommon in the literature. The most notable example of such studies are the NREL Unsteady Aerodynamics Experiments (UAE) (Hand et al., 2001). Phase VI of those experiments involved a $10 \mathrm{~m}$ diameter, stall regulated $20 \mathrm{~kW}$ wind turbine consisting of two twisted and tapered blades. The turbine was well equipped with measurement instrumentation, including five-hole pressure probes. While the Phase VI report (Hand et al., 2001) does not include experimental results from the project, the report does provide equations necessary to convert flow pitch and span-wise flow angles relative to the probe to flow angles with respect to the blade. The Local Flow Angle (LFA) and Span-wise Flow Angle (SFA) relative to the blade chord are defined as (Hand et al., 2001):

$L F A=\arctan \frac{\cos \alpha_{p} \cos \left(\beta_{p}+\epsilon\right) \sin \theta+\sin \alpha_{p} \cos \theta}{\cos \alpha_{p} \cos \left(\beta_{p}+\epsilon\right) \cos \theta-\sin \alpha_{p} \sin \theta}$

$S F A=\arctan \frac{\cos \alpha_{p} \sin \left(\beta_{p}+\epsilon\right)}{\cos \alpha_{p} \cos \beta_{p}+\epsilon \cos \theta-\sin \alpha_{p} \sin \theta}$

where $\alpha_{p}$ is the local flow angle with respect to the probe, $\beta_{p}$ is the span-wise flow angle with respect to the probe, $\epsilon$ is the span-wise probe angle offset and $\theta$ is the local flow probe angle offset. These angles are shown in Figures 1 and 2 where the SFA is positive when flow moves outboard toward the tip. Local flow angle measurements from the NREL experiments (Hand et al., 2001) were analyzed and presented as angle of attack measurements in Schepers and van Rooij (2008) after a correction for induction due to the bound circulation was applied via the Biot-Savart law. Similar corrections were applied for other pressure probe experiments by Butterfield (1989) and surface pressure methods by Shen et al. (2009).

Five-hole pressure probes at $38.5 \%$ and $55.8 \%$ radius were used by Maeda and Kawabuchi (2005) to measure the angle of attack for a three-bladed, $10 \mathrm{~m}$ diameter, upwind turbine in the open environment with yaw positions $(\gamma)$ of $-45^{\circ}$ to $+45^{\circ}$ in increments of $15^{\circ}$. Results of their experiments showed that at a $0^{\circ}$ yaw-offset the inflow velocity measured throughout the blade rotation (azimuthal angle $\phi$ ) was essentially constant although they found a variation in $\alpha$ of as much as $2.5^{\circ}$ with azimuthal position that they described as the influence of the atmospheric boundary layer (Maeda and Kawabuchi, 2005). 
Wind Energ. Sci. Discuss., doi:10.5194/wes-2016-57, 2017

Manuscript under review for journal Wind Energ. Sci.

Published: 12 January 2017

(c) Author(s) 2017. CC-BY 3.0 License.

(c) (i)
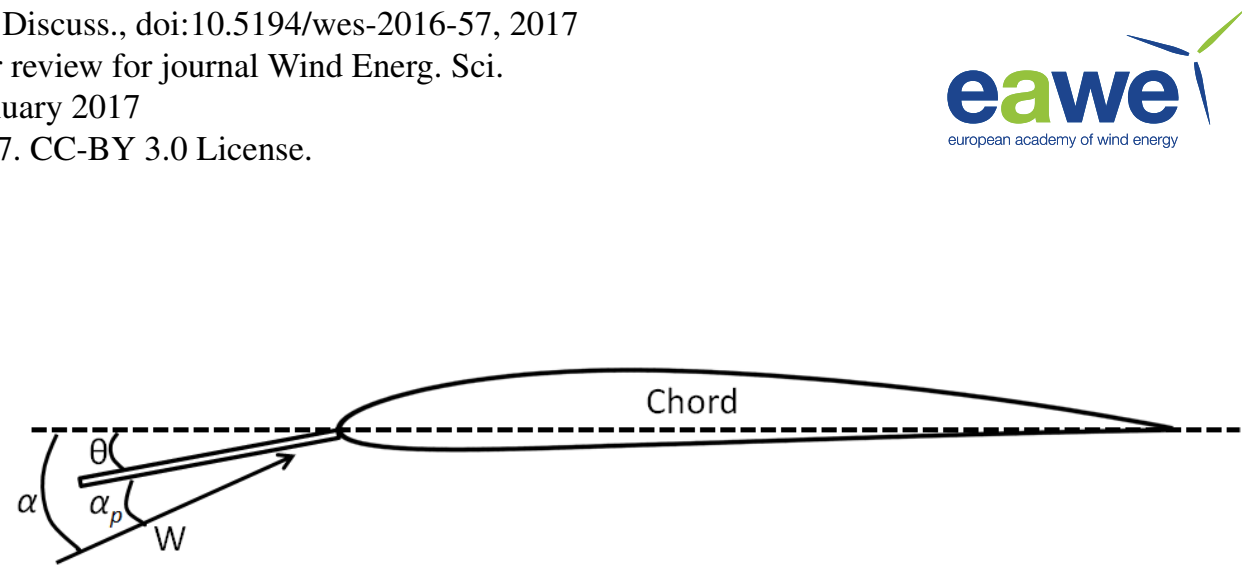

Figure 1. Demonstrative diagram of flow angles relative to the airfoil profile

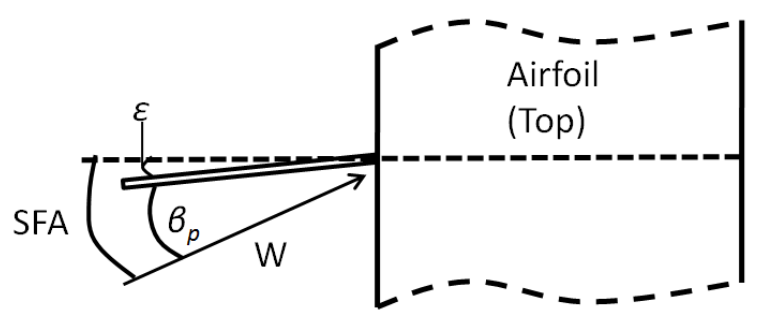

Figure 2. Demonstrative diagram of flow angles relative to the airfoil (plan view)

However, when the turbine was yawed $\pm 45^{\circ}$ relative to the upstream wind direction, the inflow velocity fluctuated significantly with azimuthal position, increasing as the blade rotated towards the wind and decreasing as the blade rotated away from the wind. In the yawed conditions the angle of attack was observed to vary differently than the flow velocity, reaching a minimum when the velocity was at a maximum for the $-45^{\circ}$ yaw case and remaining relatively constant throughout the rotation during the $+45^{\circ}$ yaw case. The variation in the angle of attack was found to be as high as $10^{\circ}$ throughout the blade rotation.

Directional pressure probes are not the only method being used to measure the angle of attack at a radial location on a wind turbine blade. In an early study Butterfield et al. (1991) used a flow angle probe to determine angle of attack at no yaw and a $30^{\circ}$ yaw case showing significant variation in angle of attack near the tower of the downwind turbine. Johnson et al. (2012) conducted experiments using a three bladed $3.4 \mathrm{~m}$ diameter turbine installed in a large-scale wind generation research facility. Wind turbine blade performance was measured indirectly via simultaneous measurements of the wind turbine output and the wind velocity upstream and downstream of the rotor. Using the measured velocities, Johnson et al. (2012) used methods described by Hansen et al. (1998) and Johansen and Sørensen (2004) to calculate the axial and tangential induction factors, $a$ and $a^{\prime}$, respectively. These values were then used to calculate the blade angle of attack. Johnson et al. (2012) found that the method resulted in angle of attack estimates within 15-20\% of airfoil design data indicating that the use of velocity measurements to validate five-hole probe measurements may be appropriate.

Multi-hole probes have also been used to characterize the flow field upstream of a wind turbine. Recently, Petersen et al. (2015) developed a method for evaluating the upstream flow velocity, axial induction factor and inflow turbulence by extrapo- 
Wind Energ. Sci. Discuss., doi:10.5194/wes-2016-57, 2017

Manuscript under review for journal Wind Energ. Sci.

Published: 12 January 2017

(c) Author(s) 2017. CC-BY 3.0 License.

(c) (i)

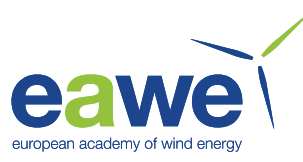

lating flow measurements at the leading edge of the blade. The method begins with the actuator disc model, which relates the velocity at the wind turbine rotor, $U_{d i s c}$, to the upstream wind velocity, $U_{\infty}$, via the axial induction factor, $a$ :

$U_{\text {disc }}=U_{\infty}(1-a)$

The axial velocity at the disc is calculated using the angle of attack and flow velocity measurements of the five-hole probe to determine the flow velocity in cartesian coordinates $u, v, w$, and subtracting the contribution to the relative wind speed caused by the rotation of the blade (Petersen et al., 2015). The axial wind vector component, $u$, is affected by the axial induction of the rotor, which can be calculated using an equation derived by Madsen et al. (2010):

$a=0.0892 C_{T}^{3}+0.0545 C_{T}^{2}+0.2512 C_{T}$

where $C_{T}$ is the thrust coefficient derived from the loading on the actuator disc, expressed via the lift and drag coefficients projected to the axial direction, $C_{y}$ (Madsen et al., 2010):

$C_{y}=C_{l} \sin (\phi)-C_{d} \cos (\phi)$

The infinitesmal thrust $d T$ on an annular element of length $d r$ can then be defined as (Madsen et al., 2010):

$d T=\frac{1}{2} \rho V_{r e l_{x y}}^{2} C_{y} c N_{B} d r$

where $V_{r e l_{x y}}$ is the relative velocity projected onto a section of the blade, $N_{B}$ is the number of blades and $2 \pi r$ is the swept distance of the blade element. The local thrust coefficient is then defined as:

$C_{T}=\frac{d T}{\frac{1}{2} \rho U_{\infty}^{2} 2 \pi r d r}=\frac{V_{r e l_{x y}}^{2} C_{y} c N_{B}}{U_{\infty}^{2} 2 \pi r}$

By assuming an initial $U_{\infty}$ value and iterating through equations (7), (4) and (3), the upstream wind profile can be calculated. Petersen et al. (2015) demonstrated the method using five-hole probe measurements taken from the DANAERO project (Madsen et al., 2010), as well as simulations. The method proposed was shown to provide accurate estimations of the flow field upstream when compared with independent measurements and simulations.

\section{Theoretical Models}

While experimental measurements of the wind turbine blade angle of attack are lacking in the literature, several theoretical models for the variation in $\alpha$ with azimuthal position and yaw angle have been developed. The simplest model for calculating 
Wind Energ. Sci. Discuss., doi:10.5194/wes-2016-57, 2017

Manuscript under review for journal Wind Energ. Sci.

Published: 12 January 2017

(c) Author(s) 2017. CC-BY 3.0 License.

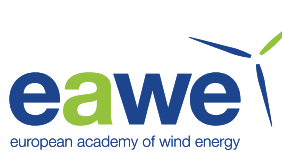

the angle of attack can be derived from the basic velocity relationships for an airfoil, where the angle of attack, $\alpha$, is defined as the angle between the rotational velocity of the turbine rotor and the relative wind velocity vector, $W$. This geometric angle of attack can be determined using equation (8) (Morote, 2015):

$\alpha_{\text {geom } 0}=\arctan \frac{\cos \beta-\lambda_{r} \sin \beta}{\lambda_{r} \cos \beta+\sin \beta}$

5 where $\alpha_{\text {geom } 0}$ is the geometric angle of attack in axial flow conditions, $\beta$ is the blade pitch at the radial location of interest, $r$, and $\lambda_{r}$ is the local speed ratio at the same location.

While equation (8) is appropriate for a quick estimation of the blade angle of attack, the error associated with neglecting the axial and tangential flow induction factors ( $a$ and $a^{\prime}$, respectively) associated with the turbine in a three-dimensional space can be detrimental to the accuracy of the prediction. When the wind turbine is yawed, determining the angle of attack becomes more complex as it varies with the azimuthal position of the blade, $\phi$. Burton et al. (2011) present a more complete model for calculating the angle of attack by combining several models and correction factors to accomodate these variations.

While the model reported by Burton et al. (2011) has historically been considered sufficient, a more recent publication by Morote (2015) presents a new model for calculating the effective angle of attack, $\alpha_{e f f}$, based again on the geometric angle of attack defined in equation (8). In this model, interference functions are defined to accommodate the axial interference and span-wise interference, labeled as $f(r)$ and $g(r)$ respectively. From Morote (2015),

$f(r) \approx 1-\frac{a_{0} \lambda_{r}}{\left(1+\lambda_{r}{ }^{2}\right) \tan \left(\alpha_{\text {geom } 0}\right)}$

where $a_{0}$ is the radially dependent induction factor for axial flow at the blade lifting line, and

$g(r) \approx-\sqrt{A^{2}+B^{2}}$

where

20

$$
\begin{aligned}
& A=\frac{a_{a 0}}{\left(1+\lambda_{r}^{2}\right)^{2} \tan \left(\alpha_{\text {geom } 0}\right)}\left(\frac{\lambda_{r}\left(1+\lambda_{r}^{2}\right)(r / R)}{2\left(1+a_{a 0}\right)}\right) \\
& B=\frac{a_{a 0}}{\left(1+\lambda_{r}^{2}\right)^{2} \tan \left(\alpha_{\text {geom } 0}\right)}\left(\lambda_{r}{ }^{2}-1-\frac{2 \lambda_{r}}{\sin \left(2 \alpha_{\text {geom } 0}\right)}\right)
\end{aligned}
$$

Here, $a_{a 0}$ is the radially dependent azimuthally averaged induction factor for axial flow. The equation for $g(r)$ is only valid at certain radial positions, which means a phase shift $\Delta$ is also required. This phase shift accounts for the change in azimuthal 
Wind Energ. Sci. Discuss., doi:10.5194/wes-2016-57, 2017

Manuscript under review for journal Wind Energ. Sci.

Published: 12 January 2017

(c) Author(s) 2017. CC-BY 3.0 License.

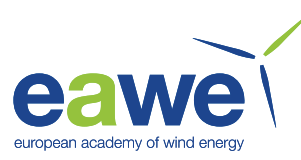

position of the blade as an air particle travels over the blade chord, which would result in a slight variation in the angle of attack along the chord line. The phase shift can be calculated as:

$\Delta \approx \arctan \left(\frac{B}{A}\right)$

Combining the interference functions and phase delay with the geometric model identified in equation (8), the Morote (2015)

5 model for calculating the effective angle of attack is defined as:

$\sin \alpha_{e f f}=\sin \alpha_{g e o m}[f(r)+g(r) \delta \sin (\phi+\Delta)]$

where $\delta$ is $\sin \gamma$.

While Morote (2015) has compared modeled pressure distributions over the blade to experimental data, neither Burton et al. (2011) or Morote (2015) present any experimental measurements of the angle of attack to validate their mathematical models. In fact, other than the studies discussed previously, there is a significant lack of experimental validation data concerning the variation in the angle of attack with turbine yaw and azimuthal position.

\section{Development and Calibration of a Five-Hole Pressure Probe}

The custom five-hole pressure probe and in-blade data acquisition system (DAQ) used here was constructed and calibrated in-house and described in Moscardi and Johnson (2016). The probe was calibrated in an open jet wind tunnel for pitch and yaw positions of $\pm 50^{\circ}$. Calibration experiments were conducted at the blade design Reynolds number with several methods evaluated to determine pressure coefficients.

Moscardi and Johnson (2016) used cubic interpolation, as well as equation (1) to calculate $\alpha$ from pressure distribution measurements. More DAQ and blade details are provided in the following section.

\section{Experimental Methods}

All experiments were conducted at the University of Waterloo Wind Generation Research Facility, which houses a fan bank capable of generating wind speeds up to $13 \mathrm{~m} / \mathrm{s}$ in a facility $15.4 \mathrm{~m}$ wide, $19.5 \mathrm{~m}$ long, $7.8 \mathrm{~m}$ high at the sides. Flow fields generated by the facility have turbulence intensities in the range of $5.9 \%$ to $6.2 \%$, and the blockage ratio of the test turbine in the facility is approximately $7 \%$. The combination of high turbulence and low blockage is considered ideal for wind turbine testing, as it is representative of the environmental conditions that wind turbines would be exposed to in the field. More detailed information about the facility geometry and generated flow field can be found in Moscardi and Johnson (2016).

The test turbine is a custom-built $3.4 \mathrm{~m}$ diameter upwind horizontal-axis wind turbine, pictured in Figure 3 . The rotor for these experiments consisted of one 3D-printed blade formed from five identical modules and two dynamically balanced rods. 


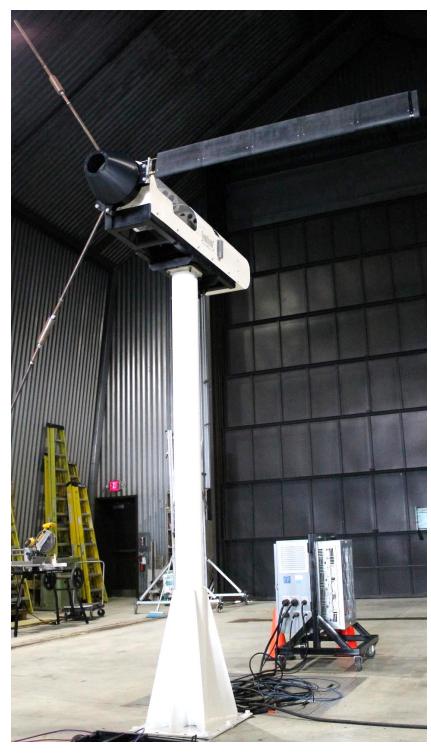

Figure 3. Wind Energy Group Test Turbine

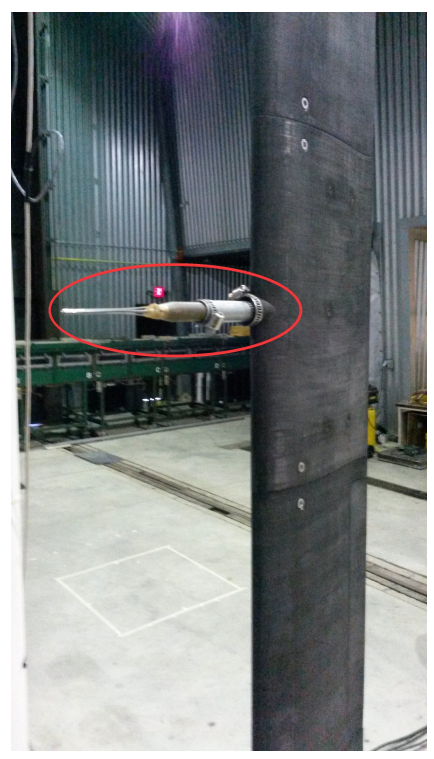

Figure 4. Five-Hole Probe Installed in Blade

The blade, described in Abdelrahman and Johnson (2014), was designed for a tip speed ratio of 4.2. The blade radius is $1.7 \mathrm{~m}$ with a constant $178 \mathrm{~mm}$ chord (c) S833 airfoil and $6^{\circ}$ pitch.

A separate blade module developed by Moscardi and Johnson (2016) was used to house the five-hole pressure probe and corresponding electronics. The electronics board consisted of five differential pressure transducers mounted to a custom-built circuit board which converted analog voltages to a digital signal transmitted wirelessly via a Bluetooth transmitter. This modular configuration allowed the probe and electronics to be installed at different radial locations on the blade without significant modifications to the blade. The probe extended $0.8 c$ out from the leading edge at an angle approximately $15^{\circ}$ offset from the chord and is shown installed in the blade in Figure 4. Further details concerning the five-hole probe can be found in Moscardi and Johnson (2016) and Gallant and Johnson (2016).

Testing was conducted at $\lambda=5.0,3.6$ and 3.1 with the probe installed at $r / R=0.55$ and 0.72 . The yaw position, $\gamma$, was varied from $-15^{\circ}$ to $+15^{\circ}$ in increments of $5^{\circ}$. A summary of the test configurations completed is provided in Table 1 . Before testing, each pressure transducer was calibrated individually to generate a calibration curve suited to the experimental testing conditions. Preliminary validation experiments were also conducted by simultaneously measuring the angle of attack with the five-hole pressure probe and a sonic anemometer using the method described by Johnson et al. (2012). Results of these experiments are not discussed here, but did show that the five-hole probe provided accurate measurements of the flow over the leading edge of the blade while also requiring less manual, repetitive intervention than the sonic anemometer required.

The experimental conditions were also used as input parameters for modeling the variation in $\alpha$ using the method described by Morote (2015). Wind speeds of $7.1 \mathrm{~m} / \mathrm{s}, 10.0 \mathrm{~m} / \mathrm{s}$ and $11.5 \mathrm{~m} / \mathrm{s}$ were implemented with a constant turbine rotational speed of $200 \mathrm{rpm}$. The geometry of the blade, as well as the range of test conditions described, were also used. To estimate the axial 
Wind Energ. Sci. Discuss., doi:10.5194/wes-2016-57, 2017

Manuscript under review for journal Wind Energ. Sci.

Published: 12 January 2017

(c) Author(s) 2017. CC-BY 3.0 License.

Table 1. Summary of Test Configurations

\begin{tabular}{|c|c|c|}
\hline & Range & Units \\
\hline$U_{\infty}$ & {$[7.1,10.0,11.5]$} & $\mathrm{m} / \mathrm{s}$ \\
\hline Rotational Speed & 200 & $\mathrm{rpm}$ \\
\hline$\lambda$ & {$[5.0,3.6,3.1]$} & - \\
\hline$\gamma$ & {$[+15: 5:-15]$} & $\circ$ \\
\hline$r / R$ & {$[0.55,0.72]$} & - \\
\hline
\end{tabular}

induction factor, the PROPID (PROPID, 2016) code used to originally design the blade was used to iteratively calculate the influence of the blades on the flow field. Inputs to the PROPID model included the design speed and dimensions of the blade, the number of blades, lift and drag coefficients for the S833 airfoil (Somers, 2005), and the Prandtl tip loss model (PROPID, 2016). For more information on the PROPID model implementation, refer to Abdelrahman and Johnson (2014). Estimates of

5 the $a$ values used based on the PROPID calculations are summarized in Table 2. These axial induction values are low but typical of a lightly loaded single blade wind turbine. The scale of these values was confirmed by the five-hole probe measurements using a method described by Petersen et al. (2015).

Table 2. Summary of Model Axial Induction Factors

\begin{tabular}{|c|c|c|c|}
\hline$r / R$ & $\lambda=5.0$ & $\lambda=3.6$ & $\lambda=3.1$ \\
\hline 0.55 & $a=0.076$ & $a=0.059$ & $a=0.042$ \\
\hline 0.72 & $a=0.104$ & $a=0.094$ & $a=0.074$ \\
\hline
\end{tabular}

\section{Results}

For all experimental results presented here a minimum of 150 data points were measured within each of the 36 azimuthal bins,

which combined with estimates of bias uncertainty in the instruments and set-up results in overall uncertainties of less than $\pm 0.3^{\circ}$. Further details of the data reduction methodology can be found in Gallant (2016). An azimuthal position of $0^{\circ}$ is defined as the test blade being in the 6 o'clock position. Axial induction factors calculated using PROPID (PROPID, 2016) were used in combination with the Biot-Savart law to adjust local flow angle measurements to the blade angle of attack.

6.1 $r / R=0.55$

Measured and modeled results for radial position $r / R=0.55$ are presented in Figures 5 and 6 for yaw positions of $0^{\circ}$ and $-15^{\circ}$, respectively. Results at $r / R=0.55, \gamma=0^{\circ}$ show that $\alpha$ is relatively constant with azimuthal position, with some variation over the azimuthal range that was also seen in the measurements of Maeda and Kawabuchi (2005). Increases in $\alpha$ appearing at approximately $\phi=100^{\circ}$ (where $\phi=0^{\circ}$ corresponds to the $6 \mathrm{o}^{\prime}$ clock position) at each tip speed ratio in the experimental data 
Wind Energ. Sci. Discuss., doi:10.5194/wes-2016-57, 2017

Manuscript under review for journal Wind Energ. Sci.

Published: 12 January 2017

(c) Author(s) 2017. CC-BY 3.0 License.

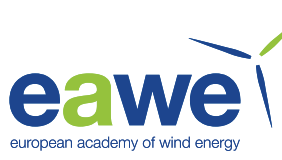

are attributed to a slight non-uniformity in the flow at the Wind Generation Research Facility, as described by Best (2010). The similar $\alpha$ values at azimuthal positions of $0^{\circ}$ and $180^{\circ}$ indicate that the effect of the wind shear is negligible in this facility in comparison to Maeda and Kawabuchi (2005) that showed considerable angle of attack variation at these azimuthal values. As would be expected given the velocity relationships at the airfoil, $\alpha$ increases as the wind speed increases and $\lambda$ decreases.

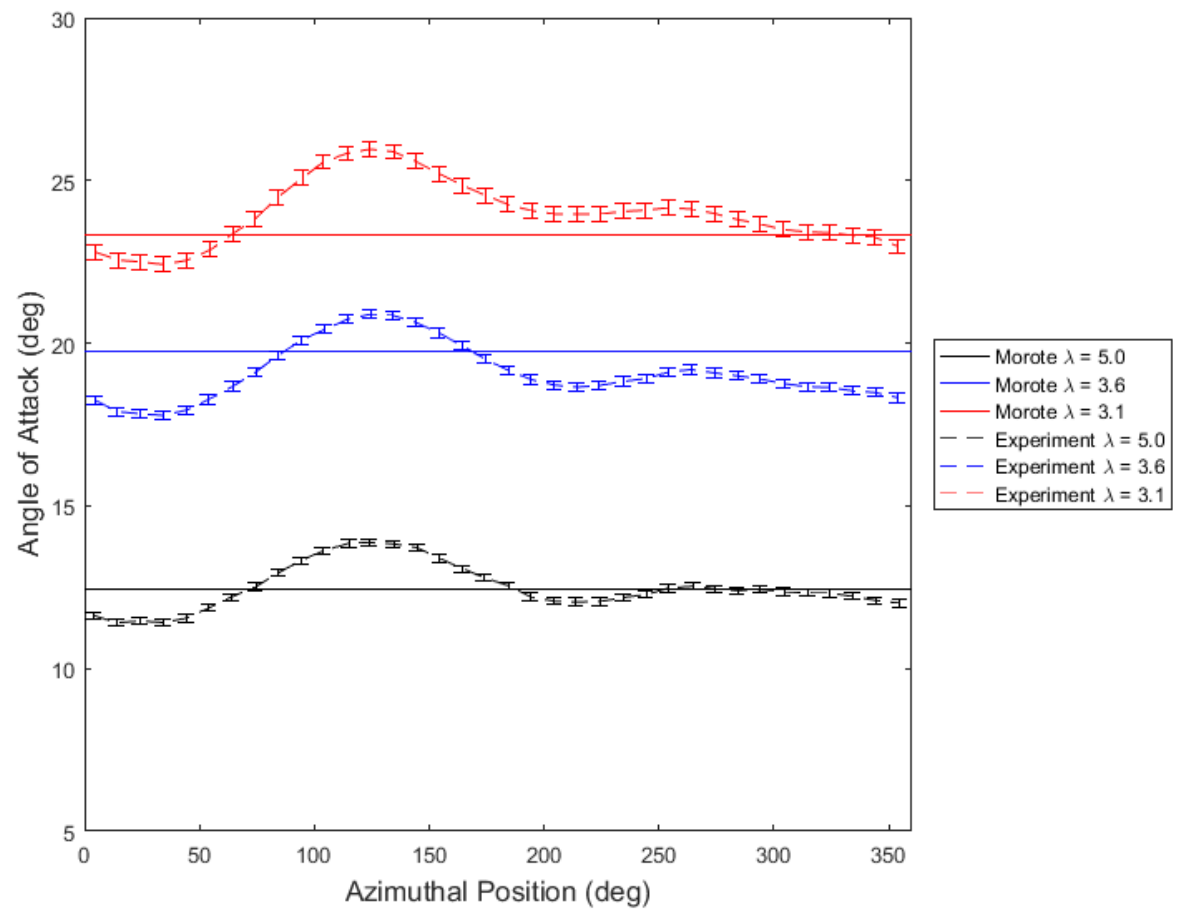

Figure 5. Measured and model $\alpha$ versus azimuthal position for $r / R=0.55, \gamma=0^{\circ}$

As the turbine is yawed $-15^{\circ}$, the experimental $\alpha$ values plotted in Figure 6 show a cyclical variation with the azimuthal position. Neglecting the effects of the non-uniformity, the angle reaches a minimum at $\phi=0^{\circ}$ when the blade rotates towards the wind and a maximum at $\phi=180^{\circ}$ when the blade rotates with the wind direction. Results at $r / R=0.55, \gamma=+15^{\circ}$ showed a similar trend. These trends agree with Maeda and Kawabuchi (2005).

The cyclical angle of attack can best be described by reviewing the effect of the yaw-offset on the idealized two dimensional velocity relationships at the airfoil. As demonstrated in Figure 7, when the blade is rotating away from the wind the upstream wind vector, $U_{\text {wind }}$, is no longer perpendicular to the blade rotation due to yaw angle $\gamma$ and the angle of attack is increased. In contrast, the angle of attack decreases as the rotor is moving into the wind. As the turbine blade rotates and cyclically moves towards and away from the upstream wind, $\alpha$ oscillates as shown in Figure 6.

Comparing the experimental results to the Morote (2015) model results shows close agreement to the experimental results. 15 At $\lambda=3.6$, the modeled values slightly overestimated the angle of attack, as can be seen in Figures 5 and 6 , though results 
Wind Energ. Sci. Discuss., doi:10.5194/wes-2016-57, 2017

Manuscript under review for journal Wind Energ. Sci.

Published: 12 January 2017

(c) Author(s) 2017. CC-BY 3.0 License.

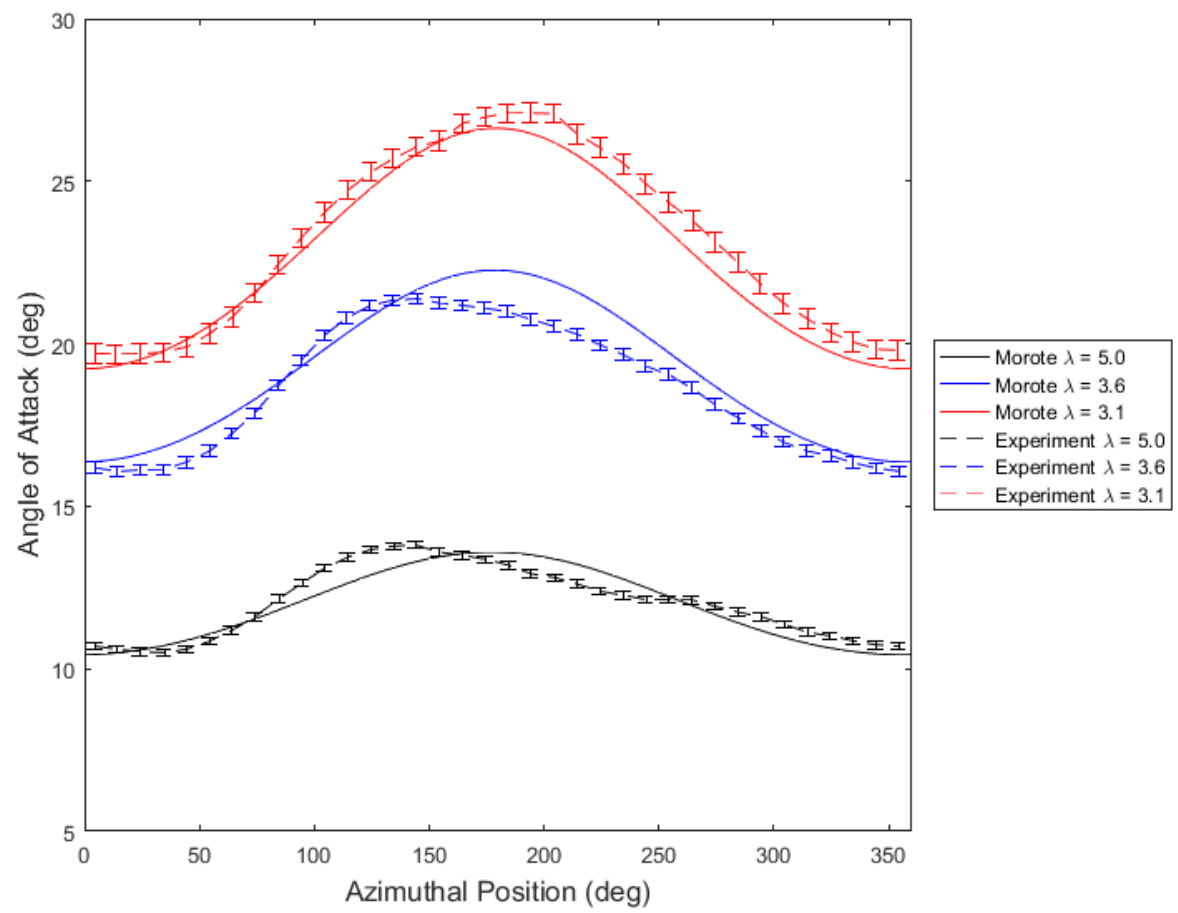

Figure 6. Measured and model $\alpha$ versus azimuthal position for $r / R=0.55, \gamma=-15^{\circ}$

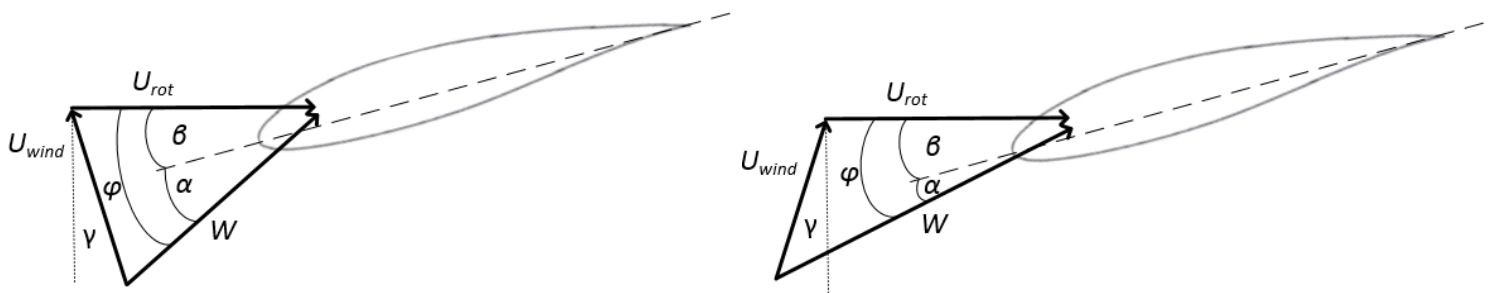

Figure 7. Demonstrative diagrams of the effect of wind direction on $\alpha$ for a blade rotating with the wind and against the wind 
Wind Energ. Sci. Discuss., doi:10.5194/wes-2016-57, 2017

Manuscript under review for journal Wind Energ. Sci.

Published: 12 January 2017

(c) Author(s) 2017. CC-BY 3.0 License.

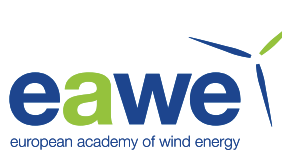

remain within $\pm 1^{\circ}$ of each other. Discrepancies at $\lambda=3.6$ are likely caused by inaccuracies in the calculated axial induction factors, as was confirmed by modeling the $\alpha$ distribution with arbitrarily changed $a$ values. However, at the lowest and highest wind speeds the experimental and theoretical values are in close agreement, indicating the potential accuracy of the modeled results.

5 Span-wise flow angles (SFA) measured at $r / R=0.55, \gamma=0^{\circ}$ are presented in Figure 8, and show that the flow over the blade is consistently oriented a minimum of $15^{\circ}$ outboard throughout the wind turbine operation. This is to be expected although the reason is under discussion (Herráez et al., 2016) at the blade root area and has been attributed to span-wise pressure gradients (Schreck et al., 2010) and centrifugal forces on the boundary layer (Guntur and Sørensen, 2014). SFA values increase as $\lambda$ decreases.

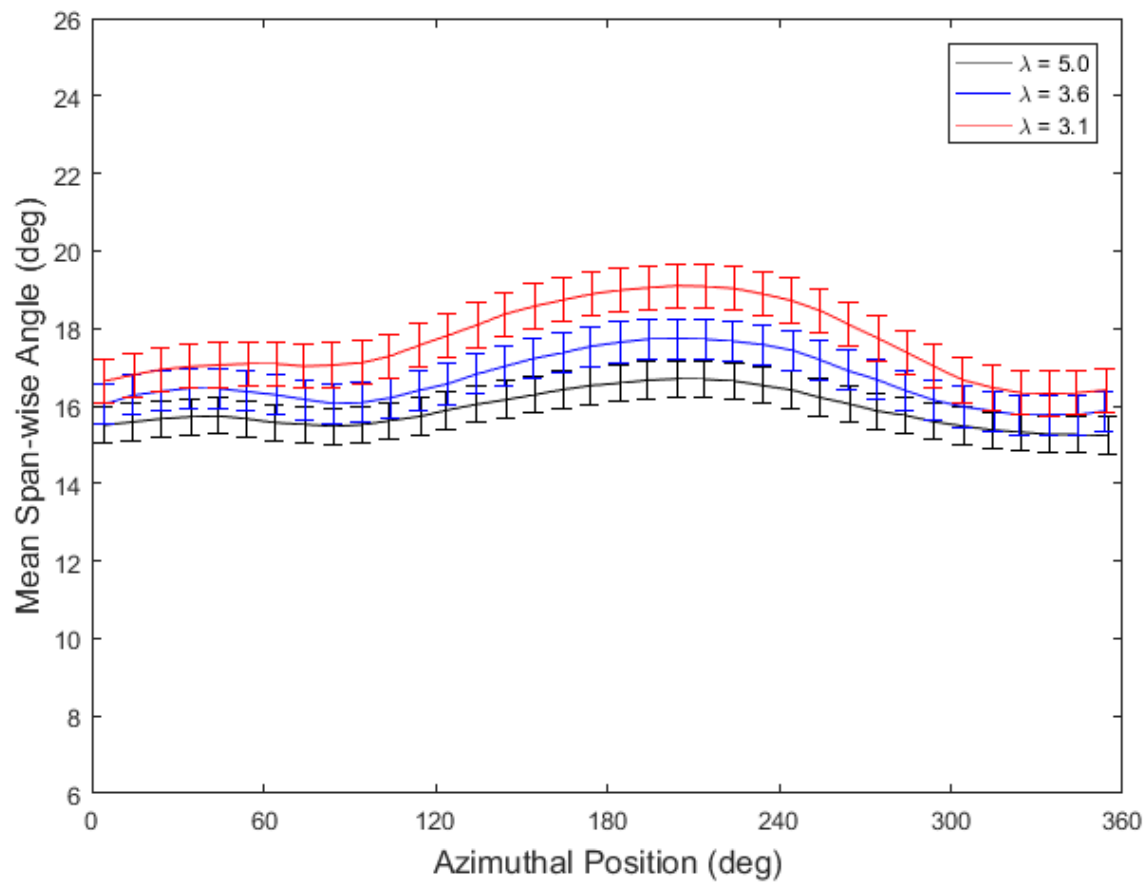

Figure 8. Measured span-wise angle (SFA) versus azimuthal position at $r / R=0.55, \gamma=0^{\circ}$

Span-wise flow angle measurements were also measured and plotted for blade rotations in non-axial flow. Results at $r / R=$ 0.55 and $\gamma=15^{\circ}$ are presented in Figure 9. Results show that when the wind turbine is yawed, the span-wise flow angle oscillates significantly throughout the blade rotation, with the amplitude of the oscillation increasing with decreasing $\lambda$.

When the turbine is yawed $+15^{\circ}$, the span-wise flow angle reached a maximum value at approximately $\psi=90^{\circ}$ and a minimum at approximately $\psi=270^{\circ}$. This can be explained by considering that, when turbine is yawed $+15^{\circ}$ and the blade is at $\psi=90^{\circ}$ (or the $9 \mathrm{o}$ 'clock position), the test blade is then oriented horizontally in space and pointed $15^{\circ}$ downstream. A portion of the upstream flow is therefore travelling parallel to the blade towards the tip of the blade, increasing the SFA. When the blade is 
Wind Energ. Sci. Discuss., doi:10.5194/wes-2016-57, 2017

Manuscript under review for journal Wind Energ. Sci.

Published: 12 January 2017

(c) Author(s) 2017. CC-BY 3.0 License.

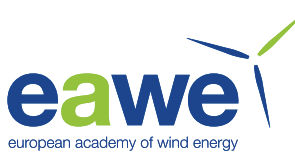

horizontal and pointed towards the upstream wind, as at $\psi=270^{\circ}$, the upstream flow speed is then travelling partially from the tip of the blade towards the hub, decreasing the SFA. The same pattern was observed when the turbine was yawed $-15^{\circ}$, though this plot was omitted due to space limitations.

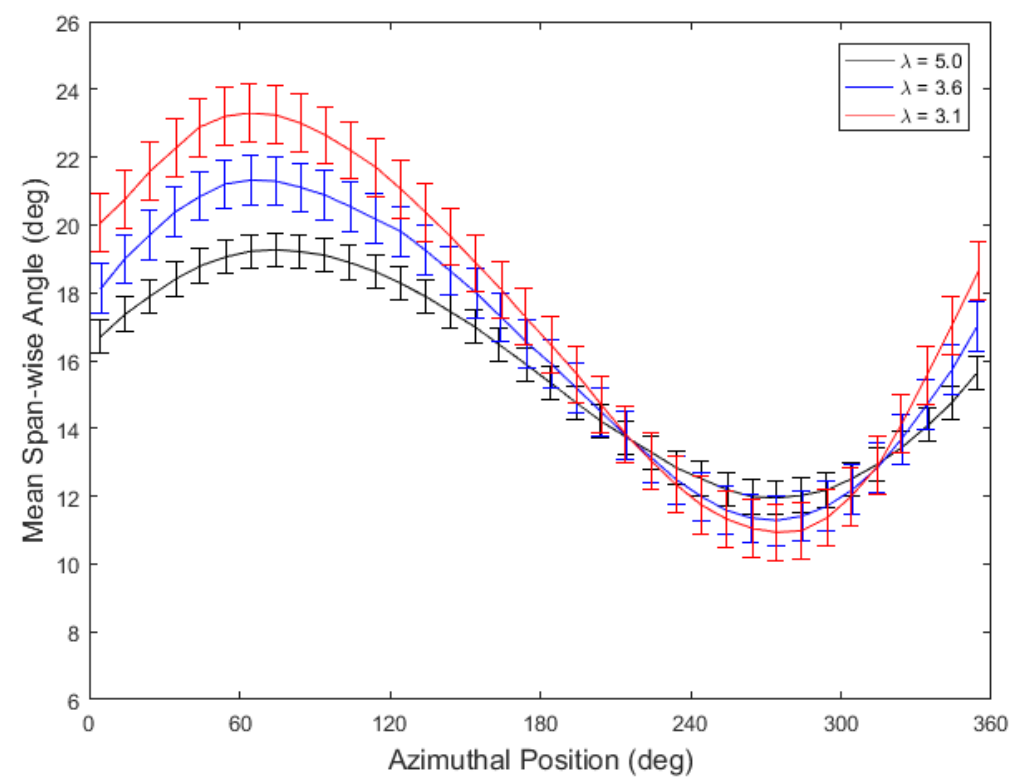

Figure 9. Measured span-wise angle versus azimuthal position at $r / R=0.55, \gamma=15^{\circ}$

\section{$6.2 r / R=0.72$}

5 Moving the five-hole probe module outboard to $r / R=0.72$ and repeating the experiments resulted in the $\alpha$ measurements presented in Figures 10 and 11 for $\gamma=0^{\circ}$ and $-15^{\circ}$, respectively. These results closer to the blade tip show a decrease in the angle of attack relative to those at $r / R=0.55$, which is to be expected given the increased tangential speed $(\Omega r)$ of the blade at $r / R=0.72$ and constant $U_{\infty}$ thus decreasing $\alpha$. In comparison to the $r / R=0.55 \gamma=0^{\circ}$ case, the measured results exceed the model predictions somewhat and the $\lambda=3.6$ experimental results are lower similar to the $r / R=0.55$ case. The effects of flow facility non-uniformity are evident at $r / R=0.72$ but the trends are similar to the $r / R=0.55$ case.

Span-wise flow angles measured at $r / R=0.72, \gamma=0^{\circ}$ are similar to those presented in Figure 8 although at a lower SFA (minimum of $12^{\circ}$ outboard) throughout the wind turbine azimuthal range, with values increasing as $\lambda$ decreases.

It should be noted that the S833 airfoil used for the modular 3D printed turbine blade stalls statically at $\alpha$ values greater than $15^{\circ}$, which would indicate that the blade would be experiencing stall at $\lambda=3.1$ given the experimental and modeled results presented. However, given that the Morote (2015) model relies purely on the geometry of the airfoil, the upstream flow characteristics and the axial induction factor, dynamic stall effects would have no effect on the modeled $\alpha$. Static stall effects 
Wind Energ. Sci. Discuss., doi:10.5194/wes-2016-57, 2017

Manuscript under review for journal Wind Energ. Sci.

Published: 12 January 2017

(c) Author(s) 2017. CC-BY 3.0 License.

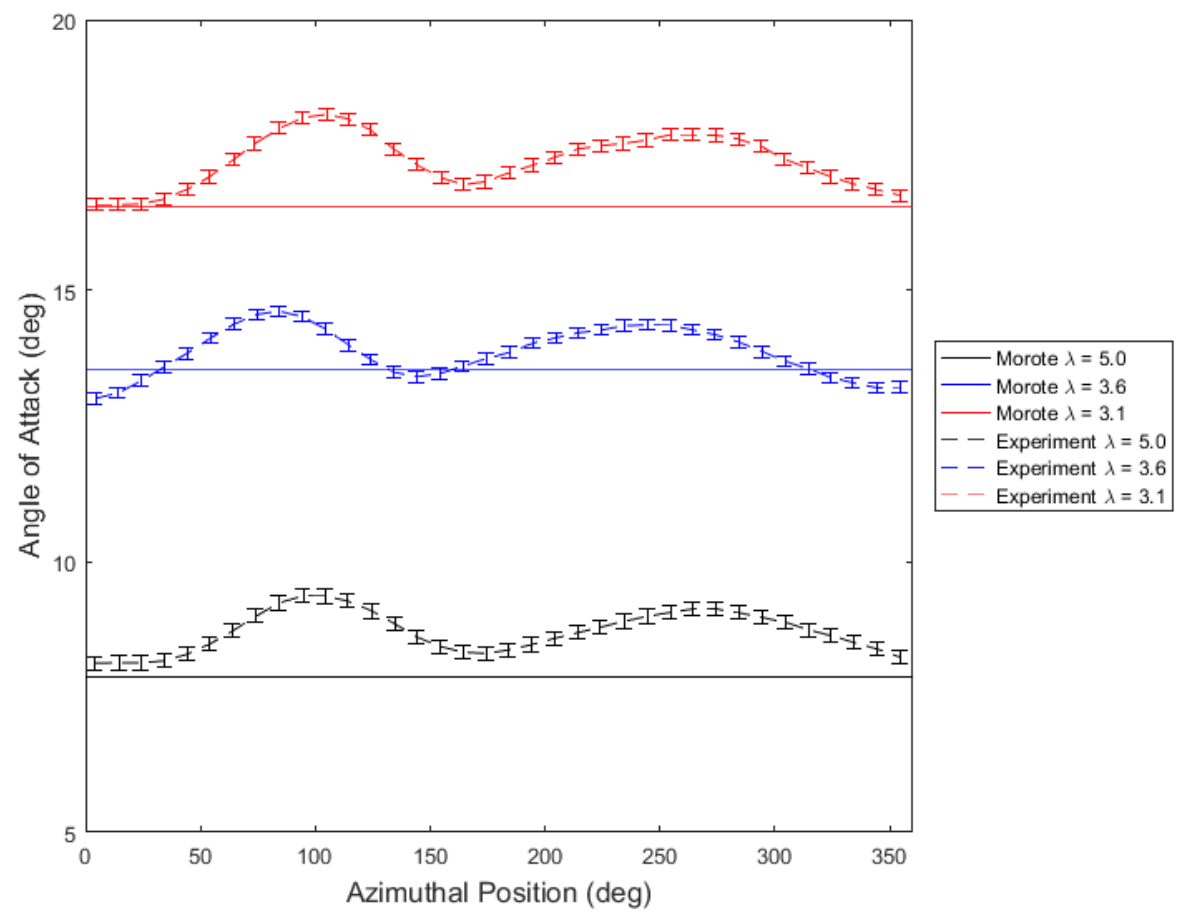

Figure 10. Measured and model $\alpha$ versus azimuthal position for $r / R=0.72, \gamma=0^{\circ}$

are included in the model via the reduced axial induction factors at the upper wind speed, as predicted by PROPID (2016). This can be inferred from the agreement between the modeled and experimental results at $\lambda=3.1$ in both Figures 10 and 11 . If blade stall due to dynamic conditions were included in the model the cyclical blade loads such as lift would be similar to those modeled by Hansen (1992), and measured and modeled by Gharali and Johnson (Gharali and Johnson, 2014, 2015; Gharali 5 et al., 2015).

\subsection{Upstream flow field}

The method proposed by Petersen et al. (2015) was implemented to characterize the flow field upstream of the wind turbine. The calculated upstream wind speeds for the $r / R=0.55$ axial tests are presented in Figure 12. It is observed that the wind speed is relatively constant with azimuthal position in all cases, which is to be expected given axial flow with a small wind turbine. The wind speeds are also in close agreement with the fan speeds implemented, as described in Section 5. The only azimuthal variation in the upstream wind speed appears to be the increase in magnitude at azimuthal positions between $\psi=$ $100^{\circ}$ and $150^{\circ}$. This non-uniformity in the flow was reflected in the angle of attack measurements presented in Figure 5. 
Wind Energ. Sci. Discuss., doi:10.5194/wes-2016-57, 2017

Manuscript under review for journal Wind Energ. Sci.

Published: 12 January 2017

(c) Author(s) 2017. CC-BY 3.0 License.

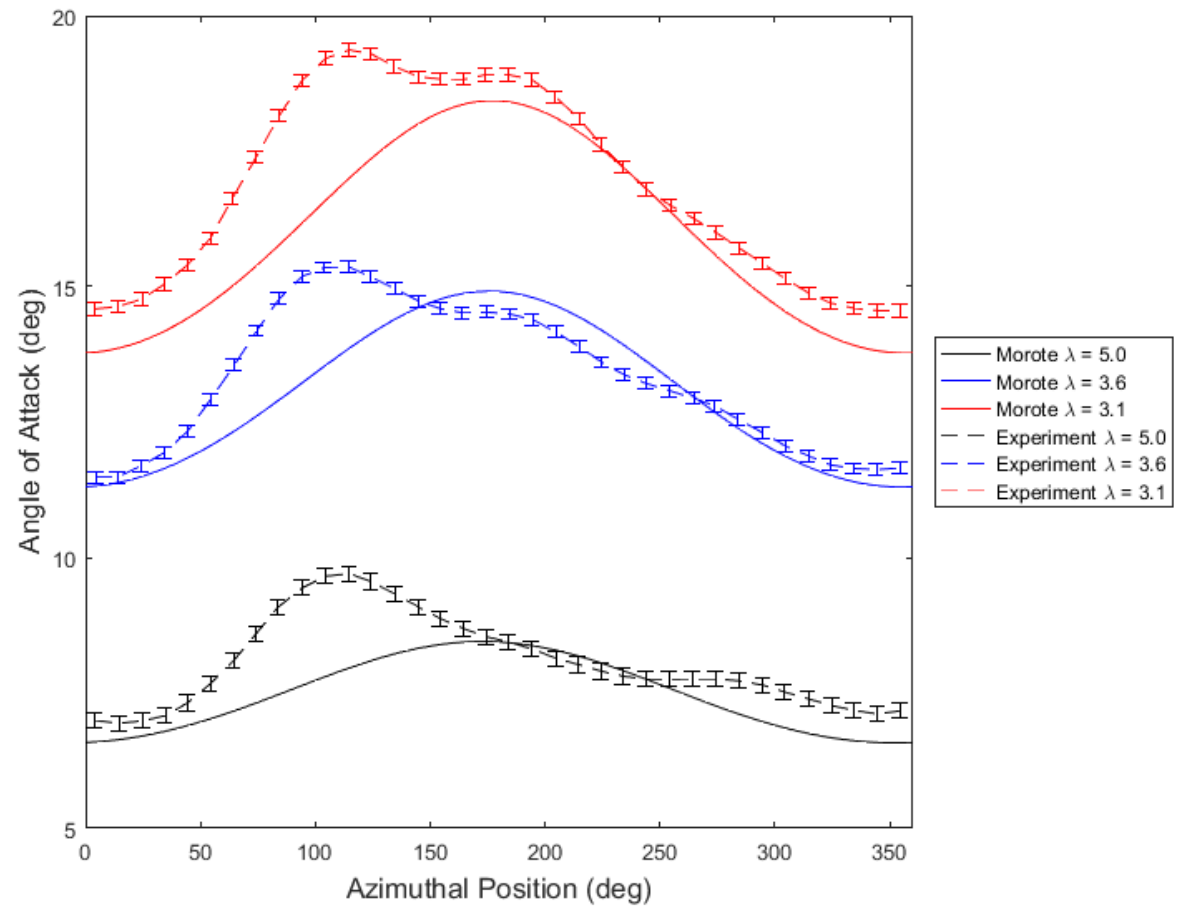

Figure 11. Measured and model $\alpha$ versus azimuthal position for $r / R=0.72, \gamma=-15^{\circ}$

\section{Conclusions}

A novel in-blade five-hole pressure probe and DAQ system was developed, calibrated, and used to measure the angle of attack at the leading edge of a wind turbine blade. Experiments were conducted to determine the variation in $\alpha$ as a function of the tip speed ratio, azimuthal position and yaw-offset. Results were compared to a model proposed by Morote (2015).

Results of the experiments showed that $\alpha$ was relatively constant with azimuthal position at a $0^{\circ}$ yaw-offset, indicating that the effect of the wind shear was negligible. When the turbine was yawed $\pm 15^{\circ}, \alpha$ was shown to vary cyclically with azimuthal position, decreasing as the blade rotated towards the wind and increasing as the blade rotated away from the wind as expected and matches the trends observed in Maeda and Kawabuchi (2005).

Comparisons with the Morote (2015) model showed agreement in the data trends between the theoretical and experimental values. Given that the model is based on known blade geometry, experimental parameters and the axial induction factor confirmed using the Petersen et al. (2015) method, discrepancies are attributed to the variability of wind conditions and induction factor predictions. Further experiments will be conducted with a three-bladed rotor, which would increase the rotor loading and axial induction factors and allow further investigation of the proposed model. 
Wind Energ. Sci. Discuss., doi:10.5194/wes-2016-57, 2017

Manuscript under review for journal Wind Energ. Sci.

Published: 12 January 2017

(c) Author(s) 2017. CC-BY 3.0 License.

(c) (i)
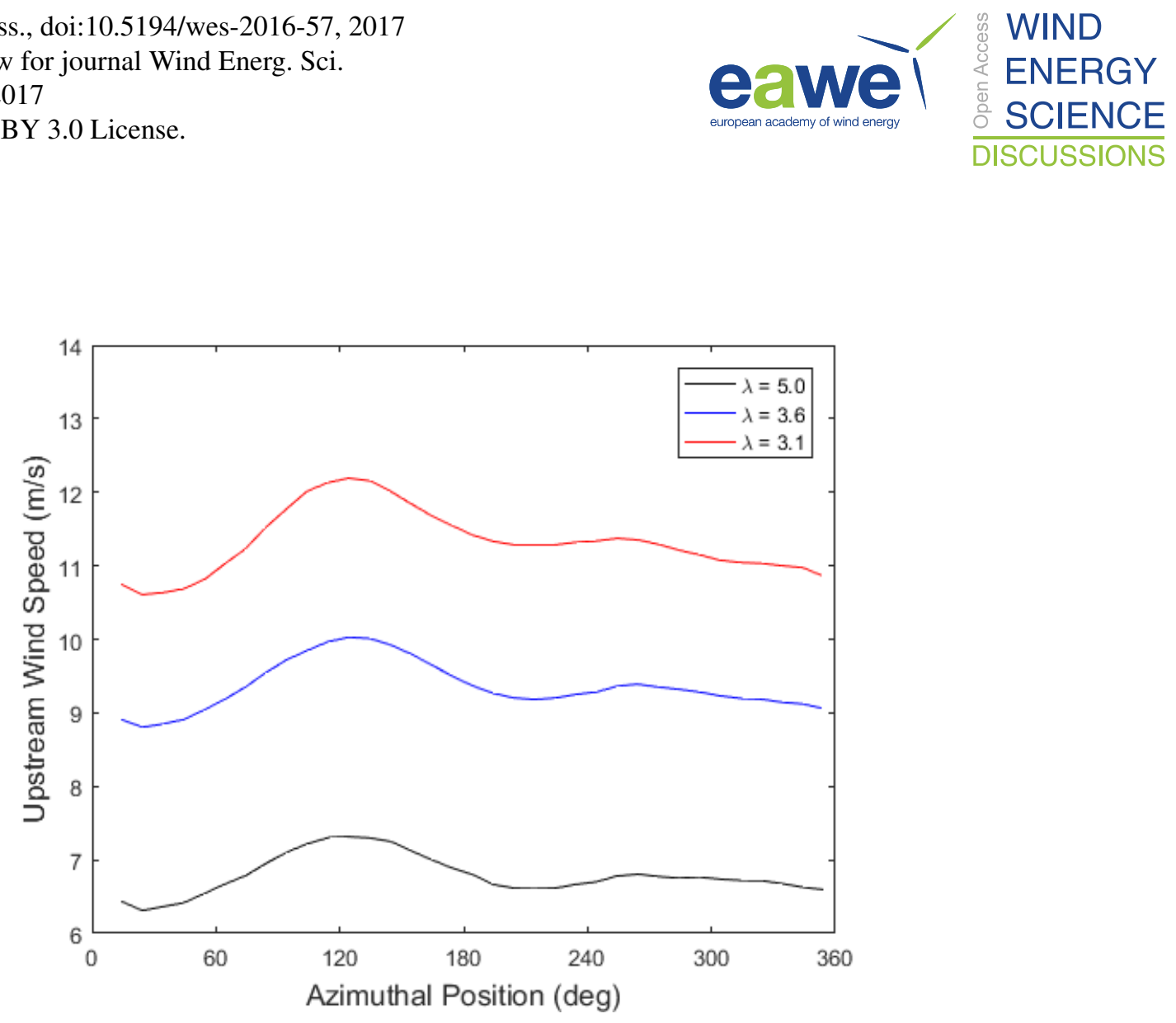

Figure 12. Calculated $U_{\infty}$ versus azimuthal position for $r / R=0.55$ using the Petersen et al. (2015) method

The results of the five-hole pressure probe experiments presented here demonstrate the potential for a compact, in-blade five-hole pressure probe and DAQ system which can measure the angle of attack directly at the leading edge of the blade. Using such technology allows for controlled measurements directly at the point of interest with low uncertainty.

\section{Data availability}

5 Data will be made available upon request.

Author contributions. D. Johnson and T. Gallant designed the experiments and T. Gallant carried them out with assistants. Both authors participated in the analysis of the results. T. Gallant and D. Johnson prepared the manuscript.

Competing interests. The authors declare that they have no conflict of interest.

Acknowledgements. The authors would like to gratefully acknowledge support from the Natural Sciences and Engineering Research Council of Canada. 
Wind Energ. Sci. Discuss., doi:10.5194/wes-2016-57, 2017

Manuscript under review for journal Wind Energ. Sci.

Published: 12 January 2017

(c) Author(s) 2017. CC-BY 3.0 License.

\section{References}

Abdelrahman, A. and Johnson, D.: Experimental Testing of Axial Load Alleviation using Trailing Edge Flaps: Static Flap Angles Case, Journal of Physics: Conference Series, 524, 012 059, doi:10.1088/1742-6596/524/1/012059, 2014.

Best, C.: Measurement of Fuel Regression Rate of a Pool Fire in Crosswind With and Without a Large Downwind Blocking Object, MASc thesis, University of Waterloo, 2010.

Burton, T., Jenkins, N., Sharpe, D., and Bossanyi, E.: Wind Energy Handbook, Wiley, Chichester, UK, 2nd edn., doi:10.1002/9781119992714, 2011.

Butterfield, C. P.: Three-Dimensional Airfoil Performance Measurements on a Rotating Wing. SERI/TP-217-3505, Tech. rep., National Renewable Energy Laboratory (NREL), 1989.

Butterfield, C. P., Hansen, A., Simms, D., and Scott, G.: Dynamic Stall on Wind Turbine Blades. NREL/TP-257-4510, Tech. rep., National Renewable Energy Laboratory (NREL), 1991.

Gallant, T. E.: Quantitative Measurement Techniques for Wind Turbine Blade Aerodynamic Performance, MASc thesis, University of Waterloo, 2016.

Gallant, T. E. and Johnson, D. A.: In-blade angle of attack measurement and comparison with models, J. Phys. Conf. Ser., 753, 072 007, doi:10.1088/1742-6596/753/7/072007, 2016.

Gharali, K. and Johnson, D. A.: PIV-based load investigation in dynamic stall for different reduced frequencies, Exp Fluids, 55, 1803, doi:10.1007/s00348-014-1803-8, 2014.

Gharali, K. and Johnson, D. A.: Effects of non-uniform incident velocity on a dynamic wind turbine airfoil, Wind Energy , 18, 237-251, doi:10.1002/we.1694, 2015.

Gharali, K., Johnson, D. A., Lam, V., and Gu, M.: A 2D Blade Element Study of a Wind Turbine Rotor Under Yaw Loads, Wind Engineering , 39, 557-567, doi:10.1260/0309-524X.39.5.557, 2015.

Guntur, S. and Sørensen, N.: A study on rotational augmentation using CFD analysis of flow in the inboard region of the MEXICO rotor blades, Wind Energy, 18, 745-756, doi:10.1002/we.1726, 2014.

Hand, M. M., Simms, D. A., Fingersh, L. J., Jager, D. W., Cotrell, J. R., Schreck, S., and Larwood, S. M.: Unsteady Aerodynamics Experiment Phase VI : Wind Tunnel Test Configurations and Available Data Campaigns, Tech. Rep. NREL/TP-500-29955, National Renewable Energy Laboratory, Golden CO, 2001.

Hansen, A. C.: Yaw dynamics of Horizontal Axis Wind Turbines. NREL/TP-442-4822, Tech. rep., National Renewable Energy Laboratory (NREL), 1992.

Hansen, M., Sørensen, N., and Michelsen, J.: Extraction of Lift, Drag and Angle of Attack From Computed 3-D Viscous Flow Around a Rotating Blade, in: EWEC 1997, Dublin, Ireland, 1998.

Herráez, I., Akay, B., van Bussel, G., Peinke, J., and Stoevesandt, B.: Detailed analysis of the blade root flow of a horizontal axis wind turbine, Wind Energ. Sci., 1, 89-100, doi:10.5194/wes-1-89-2016, 2016.

Johansen, J. and Sørensen, N.: Aerofoil Characteristics from 3D CFD Rotor Computations, Wind Energy, 7, 283-294, doi:10.1002/we.127, 2004.

Johnson, D., Abdelrahman, A., and Gertz, D.: Experimental indirect determination of wind turbine performance and Blade Element Theory parameters in controlled conditions, Wind Engineering, 36, 717-738, doi:10.1260/0309-524X.36.4.389, 2012. 
Wind Energ. Sci. Discuss., doi:10.5194/wes-2016-57, 2017

Manuscript under review for journal Wind Energ. Sci.

Published: 12 January 2017

(c) Author(s) 2017. CC-BY 3.0 License.

(c) (i)

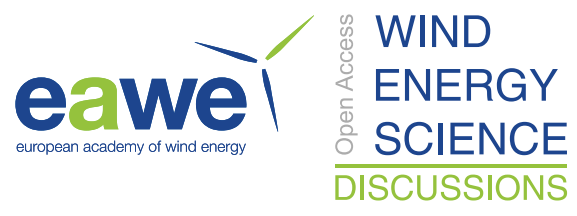

Madsen, H., Bak, C., Schmidt, U., Gaunaa, M., Fuglsang, P., Romblad, J., Olesen, N., Enevoldsen, P., Laursen, J., and Jensen, L.: The DAN-AERO MW Experiments Final report, Tech. Rep. Ris $\varnothing-R-1726(E N)$, Ris $\varnothing$ DTU, 2010.

Maeda, T. and Kawabuchi, H.: Surface pressure measurement on a rotating blade of field horizontal axis wind turbine in yawed condition, JSME International Journal Series B, 48, 156-163, doi:10.1299/jsmeb.48.156, 2005.

5 Morote, J.: Angle of attack distribution on wind turbines in yawed flow, Wind Energy, 19, 681-702, doi:10.1002/we.1859, 2015.

Moscardi, A. and Johnson, D. A.: A compact in-blade five hole pressure probe for local inflow study on a horizontal axis wind turbine, Wind Engineering , 40, 360-378, doi:10.1177/0309524X16650766, 2016.

Petersen, M., Larsen, T., Madsen, H., Larsen, G., and Toldborg, N.: Turbulent wind field characterization and re-generation based on pitot tube measurements mounted on a wind turbine, in: 33rd Wind Energy Symposium, AIAA SciTech, (AIAA 2015-1467), FL, USA, 2015.

PROPID: PROPID for Horizontal Axis Wind Turbine Design, "http://m-selig.ae.illinois.edu/propid.html", 2016.

Schepers, J. G. and van Rooij, R. P. J. O. M.: Analysis of Aerodynamic Measurements on a Model Wind Turbine placed in the NASA-Ames Tunnel. ECN-E-08-052, Tech. rep., Energy Research Centre of the Netherlands (ECN), 2008.

Schreck, S., Sant, T., and Micallef, D.: Rotational Augmentation Disparities in the MEXICO and UAE Phase VI Experiments NREL/CP500-47759, Tech. rep., National Renewable Energy Laboratory (NREL), 2010.

15 Shen, W. Z., Hansen, M. O. L., and Sørensen, J. N.: "Determination of the Angle of Attack on Rotor Blades", Wind Energy, 12, 91-98, doi:10.1002/we.277 91-98, 2009.

Somers, D. M.: The S833, S834, and S835 Airfoils. SR-500-36340, Tech. rep., National Renewable Energy Laboratory (NREL), 2005. 